\title{
RESEARCH ON THE TRANSFORMATION OF HISTORIC PATTERNS OF CULTURAL LANDSCAPE USING AERIAL PHOTOGRAMMETRY AND GEO-DATABASE: A CASE STUDY OF KULIANG IN FUZHOU, CHINA
}

\author{
Yi-Nan Lin ${ }^{1}$, Chen Yang ${ }^{2,3 *}$, Yu-Han $\mathrm{Ye}^{4}$, Zhu-Rui Zhang ${ }^{5}$ \\ ${ }^{1}$ Dept. of Landscape Architecture, East China University of Science and Technology, Shanghai, China - lynmon@ecust.edu.cn \\ ${ }^{2}$ Dept. of Landscape Architecture, Tongji University, Shanghai, China - chen.yang@tongji.edu.cn \\ ${ }^{3}$ Key Laboratory of Ecology and Energy-saving Study of Dense Habitat, Ministry or Education, Shanghai, China \\ ${ }^{4}$ Dept. of Landscape Architecture, East China University of Science and Technology, Shanghai, China - \\ 10183557@mail.ecust.edu.cn \\ ${ }^{5}$ Dept. of Landscape Architecture, East China University of Science and Technology, Shanghai, China - \\ 10180985@mail.ecust.edu.cn
}

KEY WORDS: Cultural Landscape; Historic patterns; Drone; GIS; Kuliang

\begin{abstract}
:
Cultural landscapes are the result of the interactions between cultural and natural features over time. Historic research and site investigation are two conventional methods for identifying the transformation of cultural landscapes. Over the past few decades, with the massive development of computer and internet, technologies such as aerial photogrammetry, GPS and GIS provide new approaches for the study of landscape transformation. The aim of this research is to investigate and present the transformation of a cultural landscape using aerial photogrammetry and geo-database. Kuliang in Fuzhou, a former foreigners' summer resort established by missionaries in 1886, was used as an instrumental case study. This research has identified historical mountain trails by superimposing historical maps and GPS-recorded tracks. Historic sites were found through a comparison of historical photos and low-altitude drone images. Drone-based orthophotos of the sites provide significant evidence for the restoration of the historical buildings. Furthermore, based on the integration of multiple sources of data in a geo-database, this research reveals Kuliang's landscape patterns and their transformation over time. The conclusion shows that the use of aerial photogrammetry and geo-database can effectively integrate fragmented cultural landscape information, and identify the transformation of cultural landscape patterns, thereby providing significant references for landscape heritage restoration and sustainable development.
\end{abstract}

\section{INTRODUCTION}

Cultural landscapes are the result of the interactions between cultural and natural features over time, and has important cultural heritage values. However, it has always been a difficult task in heritage conservation and management to identify the dynamic changes in the pattern of cultural landscape heritage and its cultural value. In addition to documentary research, field investigation, remote sensing and other conventional approaches, in recent years, aerial photogrammetry, GPS handhelds and GIS databases have provided important opportunities to improve the identification of the dynamic pattern of cultural landscapes.

Kuliang, a former foreigners' summer resort in Fuzhou, China was used as an instrumental case. It is situated about 15 kilometres east of the Fuzhou city. Kuliang was established by early missionaries in 1886 (Pitcher, 1895). Due to the cool climate of this area caused by the higher altitude (over 700 meters), many foreigners who cannot bear the heat of Fuzhou chose to settle in Kuliang. At least 120 stone cottages were built before 1930, but currently only 20 remained. Other cottages were mostly demolished by typhoon, fire disasters and wars. Some historical paths and ancient trees are still standing. However, today it is difficult to perceive the historic characters of Kuliang as a cultural landscape because of the fragmentation of the heritage environment.
From 1886 to 1949, the foreigners living in Kuliang took lots of photos and left a wealth of letters and diaries. They also organized the Kuliang Council, which has published a series of "Kuliang handbooks" with three historical maps. These documents are important reference for the restoration of the historical pattern of Kuliang.

However, after 1949, Kuliang was used as a summer resort of the government and then underwent continuous construction activities. The construction of winding roads, large hotels and resort facilities has greatly changed the landscape of Kuliang, creating considerable challenges for the study. Three research questions were explored in the paper:

(1) How to identify the historic patterns of Kuliang cultural landscape based on the existing historical archives, which has been continuously changed by the construction activities since 1949 ?

(2) How to add the geographical components to the fragmented individual memories (and also the collective cultural memories) that can help us to understand them better?

(3) What kind of human-land relationship is hidden behind the transformation of the historic patterns?

\footnotetext{
* Corresponding author
} 


\section{METHODOLOGY}

\subsection{Building the Kuliang geo-database}

Recognizing the characters of the cultural landscape in Kuliang area requires identifying and analysing all landscape elements and their relationships, including mountain trails, historic buildings, plantations, and farmlands. In preliminary research, the team used the topographic maps and satellite images as the basic data. However, historical maps have limitations in terms of completeness and accuracy, which makes it difficult to further understand the characteristics of cultural landscapes.

This article proposed a new methodology combing the Historic Landscape Characterisation tool (Turner, 2006) with digital technologies such as GNSS tracking, drone-based orthophotos and 3D modelling, and tried to convert documents that do not have geographic information into datasets that can be used by GIS. The geo-database was designed as a platform to integrate and analyse historical information of Kuliang (Table 1).

\begin{tabular}{|c|c|c|}
\hline Datasets & Contents & Data format \\
\hline $\begin{array}{l}\text { Individual } \\
\text { and } \\
\text { collective } \\
\text { memories }\end{array}$ & $\begin{array}{l}\text { oral history } \\
\text { letters and diaries } \\
\text { achievement } \\
\text { book chapter } \\
\text { descriptive documents }\end{array}$ & $\begin{array}{l}\text { multimedia } \\
\text { (files, photos, } \\
\text { etc.) }\end{array}$ \\
\hline $\begin{array}{l}\text { Landscape } \\
\text { features }\end{array}$ & $\begin{array}{l}\text { buildings } \\
\text { farmlands } \\
\text { plantations } \\
\text { rivers etc. }\end{array}$ & $\begin{array}{l}\text { vector, points } \\
\text { and shapes }\end{array}$ \\
\hline \multirow[b]{3}{*}{$\begin{array}{l}\text { Geographic } \\
\text { information }\end{array}$} & analysis drawings & vector \\
\hline & $\begin{array}{l}\text { historical maps } \\
\text { sketch maps } \\
\text { aerial photos }\end{array}$ & bitmaps \\
\hline & $\begin{array}{l}\text { GPS tracks } \\
\text { points cloud } \\
\text { topographic maps } \\
\text { orthophoto maps } \\
\text { satellite images } \\
\text { DEM data }\end{array}$ & $\begin{array}{l}\text { vector, object } \\
\text { file or geotiff }\end{array}$ \\
\hline
\end{tabular}

Table 1 The structure of the Kuliang geo-database

\subsection{Data processing}

Different types of data were integrated into the geo-database. The combination of geotagged files and historical maps provided reliable geographical information, and they were used to interpret the social and cultural contexts of the landscape (Thomas, 2013). based on the GIS platform, the historical maps were all georeferenced and converted into the feature map layers. The challenge comes from those sketch maps without accurate georeferenced information. Therefore, redrawing the historical maps based on the mapping of the historic environment will be a good choice (Deegan and Foard, 2008). We developed a new method using GNSS handsets to record and convert current roads and the relics of mountain paths into formatted tracks. The paths were then identified through the overlay of historical maps and current tracks.

The historical photos are significant evidences for the research as well. Interviewing the locals was the first choice for identifying the historical photos, but the application of lowaltitude drone mapping provided an efficient way to identify the locations (Richards-Rissetto, 2017). The team introduced aerial photogrammetry to create 3D model and comparing the historical photos with the current landscape. It can improve fieldwork efficiency and also provides accurate spatial data without ground control points (Hill, 2019).

Furthermore, personal memories including oral history, diaries, letters and other documents were also integrated to the geodatabase. In previous research of this area, this fragmented information is regarded as indirect evidences with limited values. There is a gap in the literature, however, regarding how the archival collections can effectively be integrated into geographic information systems (Widener and Reese, 2016). We tried to add coordinates to these documents so they can be converted into formatted location-based records (LBR) and then geo-referenced in the database for historic analysis.

\section{IDENTIFYING THE TRANSFORMATION OF THE CULTURAL LANDSCAPE PATTERN OF KULIANG}

\subsection{Rectifying the historical maps}

The earliest map of Kuliang was surveyed by Rev. Philip. W. Pitcher in 1895. While the map is a sketch without complete information of scale and annotations, the cottages that still exist today provide us with important references so that we can understand the early development of Kuliang. The Kuliang Council published a new handbook for local residents in 1919, and the map was redrawn by Paul P. Wiant, the head of the Union Architectural Service of the Methodist Episcopal Mission in Fuzhou. Wiant adopted the modern surveying and mapping technology, and the updated map was much more accurate than the Pitcher's. The Council did not publish any new maps since then.

The 1919 historical map was firstly rectified in GIS (Figure 1). Though it was surveyed by professional engineer, it still has deviations compared with modern topographic maps. Therefore, field surveys were required to further confirm the distribution of historical paths.

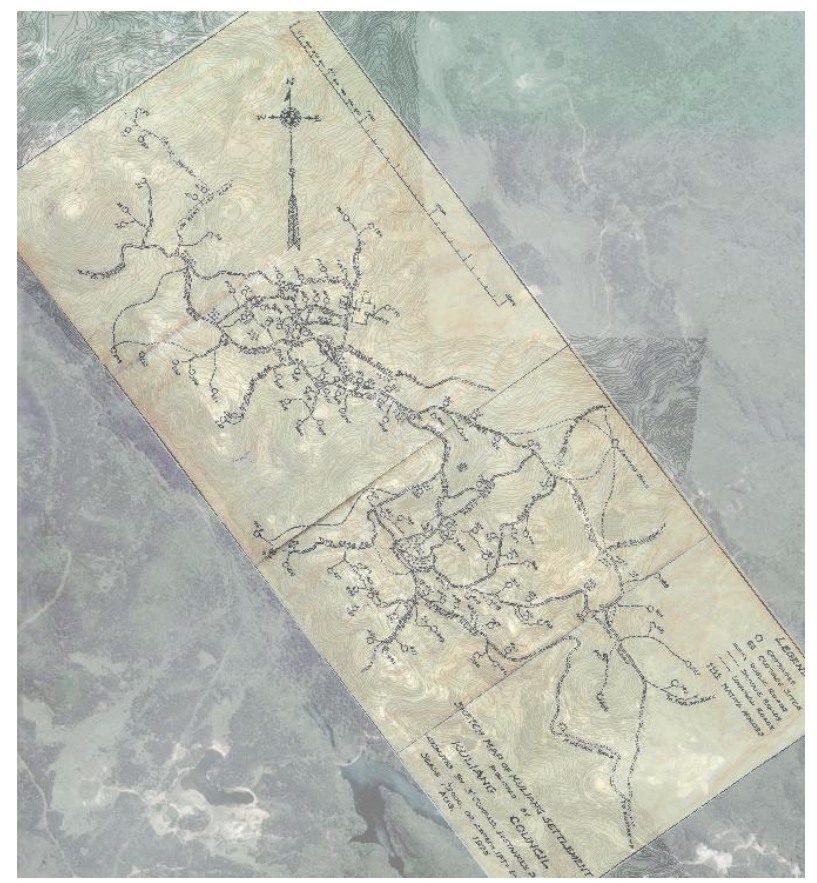

Figure 1 The rectified 1919 historical map, overlaid with the 2018 orthophoto map and 2019 topographic map 
A Garmin Colorado handheld GPS was used to correct the deviations. Taking the west corner of Kuliang as an example: We started the site observation from the former "Foochow Road", and tried to find the historical paths under the guidance of the rectified map. An old stone-paved path was discovered and soon the site of No.209 cottage was identified. The walking tracks were recorded by the handheld GPS; after being converted to a GPX file, the tracks can be shown in the GIS. By comparing the tracks with the road lines in the historical map, a new map was generated with the historical paths demonstrated (Figure 2).

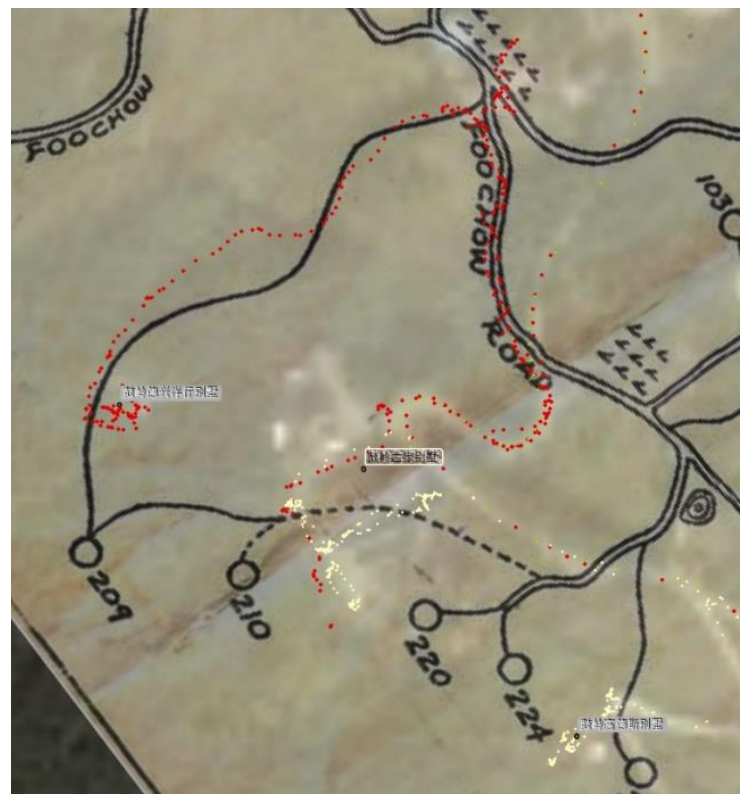

Figure 2 The 1919 Kuliang map (drawn by the missionary architect, Paul P. Wiant) was rectified roughly with the GIS

system; The red and yellow dots, recorded by a Garmin

handheld GPS, showed the track that the research team has walked to find the old cottages sites.

\subsection{Restoring the historical scenes}

Early missionaries took a series of historical photos of Kuliang, most of which showed the cottages and natural environment. They are significant evidence of the historic landscape scenes, but the dramatic changes of the environment made it difficult to identify the location (Johnston and Erh, 1994).

Following traditional fieldwork methods, the research team invited some local elderly people to help identify these photos. Some of them were identified successfully, but for others, especially the early photos, it was difficult for the locals to tell where they were taken. It is partly because many historic scenes have disappeared; on the other hand, the poor accessibility of the shooting location is the reason as well: The terraced fields which could be seen in lots of historical photos of Kuliang, are mostly covered with bushes and trees today.

The research team used different methods to identify the location of historical photos. Firstly, based on the rectified historical maps, combined with the house numbers and owners name list, some photos were confirmed to be taken within particular areas; secondly, the research team obtained the point cloud data of these areas by aerial photogrammetry, and then

${ }^{1}$ The three missions are: Church Mission Society (CMS); Methodist Episcopal Mission (MEM); American Board of Commissioners for Foreign Mission (ABCFM). compared the 3D model with historical photos; thirdly, through the field survey, the shooting locations of the historical photos were finally identified.

Siemssen \& Krohn Co. was an important tea-trading company in Fuzhou during 1860-1945. Its founder, Gustav Theodor Siemssen, owned a cottage in the eastern valley of Kuliang. The research team got several historical photos of the Siemssen's cottage from the descendants. However, most of the sites have disappeared, and it is difficult to identify the places and features in the historical photos. A DJI Mavic Air drone was used to take oblique photographic images of the valley. Through the route planning, the drone survey flied in an area covering $500 \mathrm{~m}^{2}$, taking a photo for every 5 meters. Aero triangulation was calculated by the software of ContextCapture, and finally the research team generated a 3D model of this area (Figure 3). By comparing the screenshots of the 3D model with historical photos, the research team identified the historical pattern of the landscape and its important sites.

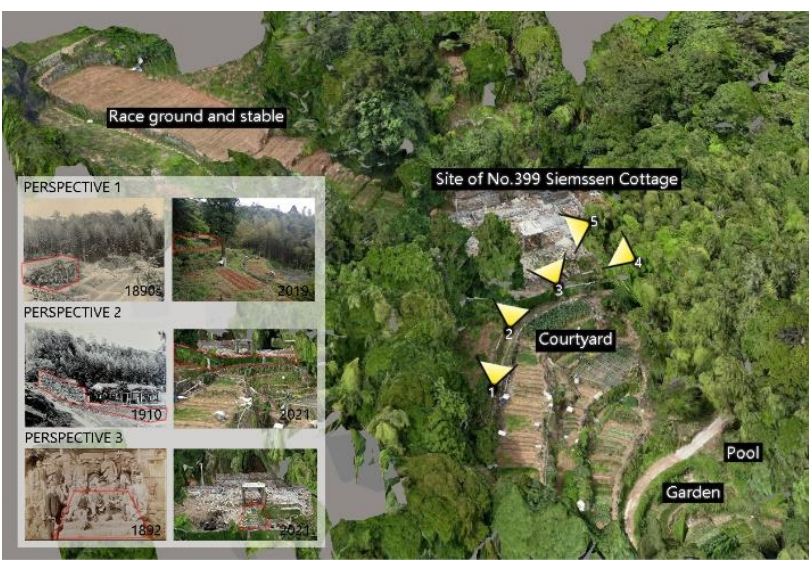

Figure 3 A 3D-Model of the Siemssen \& Krohn Co. cottage in Kuliang, generated by a DJI Mavic Air drone. It provides more chances to compare the historical photos with current situation, especially for those blocks which are under construction.

\subsection{Mapping the individual and collective memories}

The Kuliang residents left many diaries and letters. In addition, the three major missions in Fuzhou ${ }^{1}$ also kept official archives, which include the deeds for leased land, hand-drawn boundary maps and rough building plans. These materials are fragmentary, but they contain a great deal of first-hand information.

With the help of the locals, some sites hidden in the mountain were found. The research team used the drone to take highresolution orthophotos, and compared them with the original sketch plans. It enables the researchers to redraw the site plans accurately (Figure 4). The maps and plans were then rectified by GIS and became the base map for the local blocks. 


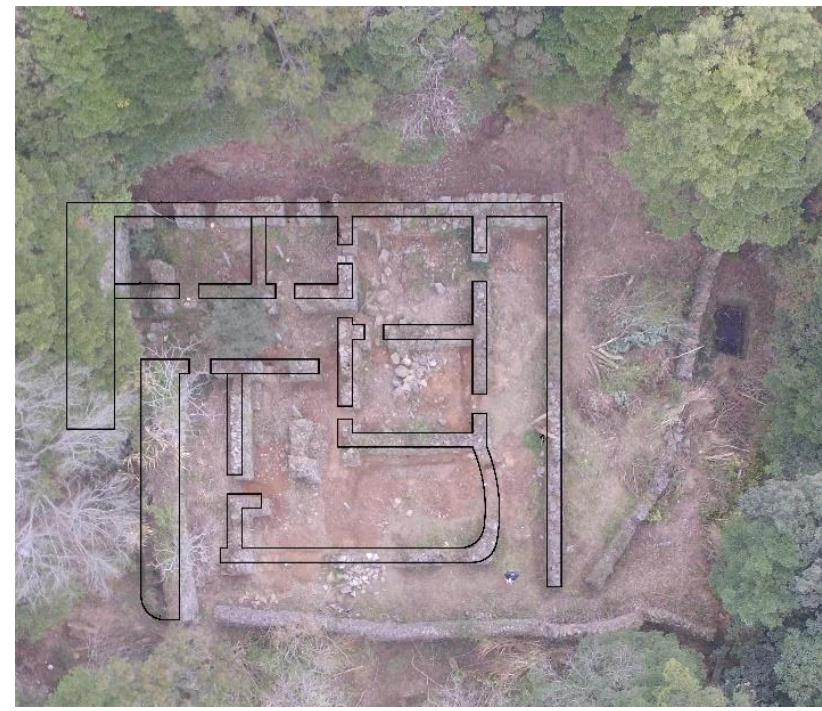

Figure 4 Site of the No.395 cottage in Kuliang, belonging to

Dr. H. R. Pakenham, a British medical missionary. With orthophotos, the research team redraw the original plan of this building.

The historical literature is subdivided into different forms. Coordinates were added to the data which can be formatted, such as the personal identities, missions, arrival and departure time; they were converted into database fields, for showing the gathering pattern. Other descriptive information, such as "one stop at a rest place on the way up at a tea house" (Macinnis, 1980) was classified according to the authors and became references.

The research team attempted to show the transformation of the housing property rights in different years:

In the early period of Kuliang (since 1895), the Anglican missionaries (from the Church Mission Society) tended to live in the centre of Kuliang, especially in Qitouding (Summitville) and Shuangguiding (near Ga-U Road) areas in the northwest; Methodist missionaries (from the Methodist Episcopal Mission) settled in the Sanbaocheng (the Club square) area. The houses of other small missions (such as ABCFM, EPM, RCA) are scattered and evenly distributed.

After 1907, Kuliang entered a stage of rapid development, the houses owned by the Anglican and the Methodist missionaries gradually occupied the dominant position, and new cottages expanded to the area of Liangcuo. The few houses of merchants were mainly distributed in the peripheral areas such as Shuangguiding and Houpulou.

When Kuliang reached its peak, the areas of Shuangguiding, Xiawai and Qitouding were all occupied by the Anglican missionaries; The areas of Sanbaocheng and Liangcuo were dominated by Methodist missionaries, and also some people from the ABCFM (Figure 5).

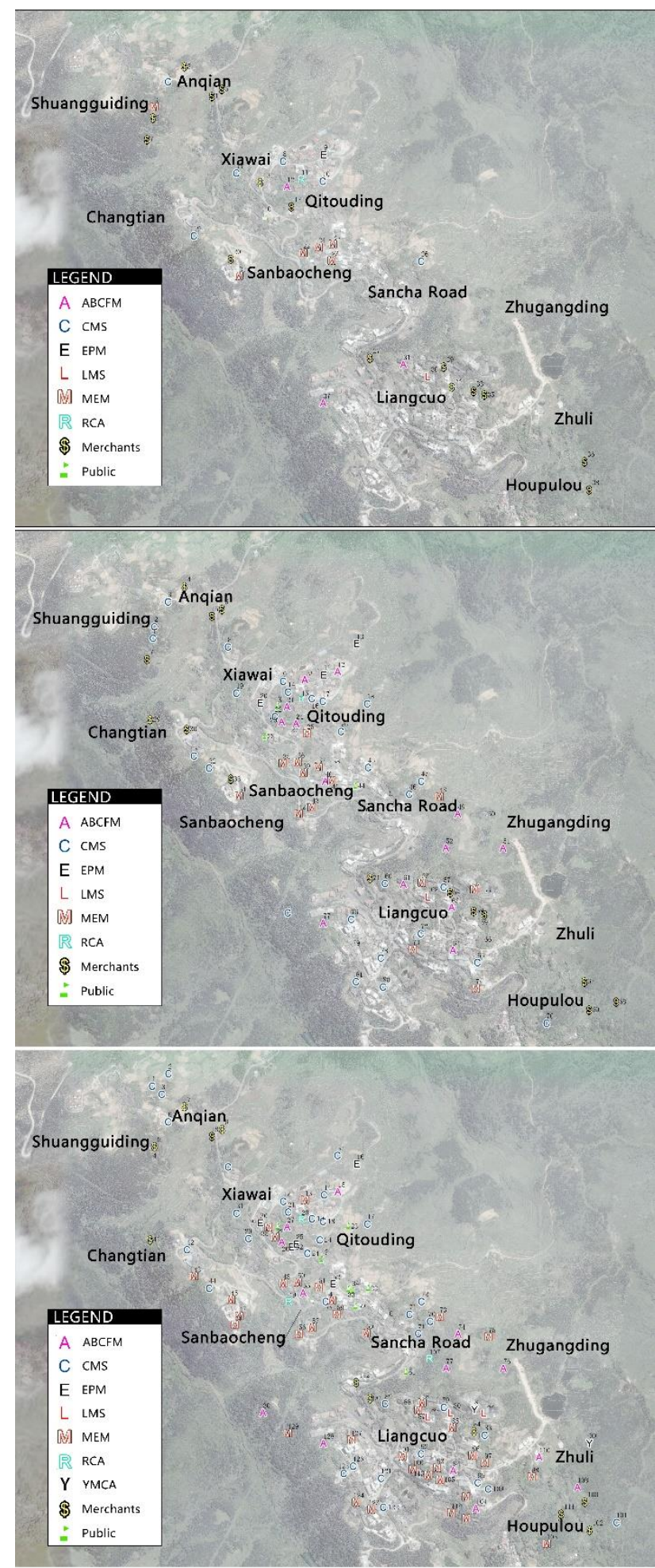

Figure 5 The distribution of the cottages in Kuliang, 1897 -

1907 - 1919. The ownership of the cottages was marked and showed the gathering pattern of the different missions on the mountain. 


\section{INTERPRETING THE TRANSFORMATION OF THE CULTURAL LANDSCAPE PATTERN OF} KULIANG

\subsection{Transformation of the gathering patterns}

In order to have a deeper understanding of the formation mechanism of Kuliang cultural landscape, this research team carried out a series of analyses. The identification and illustration of the ownership of the cottages in Kuliang provide a better recognition of the gathering pattern on the hills. The maps demonstrate that people who came from the same missions or countries preferred to live together. Early missionaries, especially the Anglicans, loved to live around Qitouding area (Summitville), where they can overlook the city of Fuzhou and the Min River. Historical materials show that the endless work almost exhausted them at that time, causing them to yearn for quiet and rest places (Welch, 2006). Therefore, some Anglicans chose to build their cottages far away, like Rev. John R. Wolfe and his family.

On the contrary, the maps show that the American missionaries loved to live around the old street where the traditional centre of Kuliang is located. Historical documents support this pattern and show that American missionaries had better communication with the locals. For example, Rev. N. J. Plumb acquired a sixyear lease of a piece of property from the locals and he built the "Rest Cottage" in 1887. The resort grew rapidly with dozens of stone cottages centring around the Stone Church on the old street in the following ten years (Caldwell, 1953).

The gathering pattern of merchants were very unique. They chose the most remote places. Through the site survey of the cottages of Siemssen \& Krohn Co., the Jardine Matheson \& Co. and some other trading companies, the research team found some pieces of enclosed lands with stone walls. These lands previously were used as tennis courts, stables and even cattle farms. Merchants needed larger tracts of land to built these places to meet the needs of their life.

\subsection{Transformation of the site-choice for the cottages}

The further analyses of the elevation, orientation and slope of these cottages show that foreigners preferred the high slopes facing deep valleys and beautiful scenery. By contrast, locals chose to build their houses in basins near terraces. However, this pattern is dynamic and always changing. In the early period since 1895, the foreigners' cottages were mainly distributed in three areas of Shuangguiding, Qitouding and Liangcuo. The building elevations of Shuangguiding were between 600 and 640 meters, and the elevations of Qitouding and Liangcuo were between 740 and 775 meters. However, when Kuliang was at its peak, newly built cottages were gradually concentrated in the Qitouding and Liangcuo areas, and the elevations of the houses dropped to between 690 and 730 meters.

This pattern transformation was mainly attributed to the climatic characteristics of this area, more specifically typhoons. Kuliang is located on the northeast of Fuzhou, where is on the windward side of the dominant wind direction with an monthly average temperature of $24.5^{\circ} \mathrm{C}$ in summer. The locals suffered from the disaster for a long period, so they chose to build their houses in sheltered places.

After the two terrible typhoons in 1899 and 1909 (Welch, 2006), the foreigners turned to learn from the locals. They built houses on slopes facing the southwest, with very thick typhoon walls on the northeast side to resist the natural disaster. The remains of the typhoon wall that still exist today are significant evidence of this period of history (Figure 6).

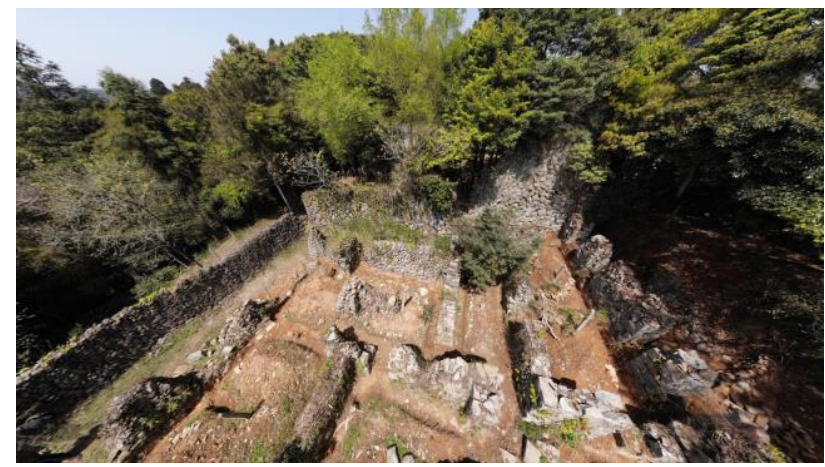

Figure 6 A drone-generated $360^{\circ}$ panorama of the No.395 cottage, showing the remaining typhoon walls

\subsection{Transformation of the plantations}

Comparing to the cottages, the plantations are more likely to be preserved, and they have become important clues or even landmarks, which can significantly reveal the historic landscape pattern of Kuliang.

Some historical archives describe the plantation in this area. In the early years, most of the hills were not covered by trees, and there were rice terraces and sweet potato fields. Bamboo groves and pine trees were also scattered on the hills (Caldwell, 1953). The plantation coverage on the hills increased rapidly in the 1930 s, and most of the cottages were "hidden among the trees" (Zhuang, 1948).

In addition to pine, Cryptomeria is one of the most common arbour trees in Kuliang. The interview with local community shows that these trees, different from the native pine trees, were planted by missionaries. Therefore, they can be considered as a sign to identify the cottage sites (Figure 7).

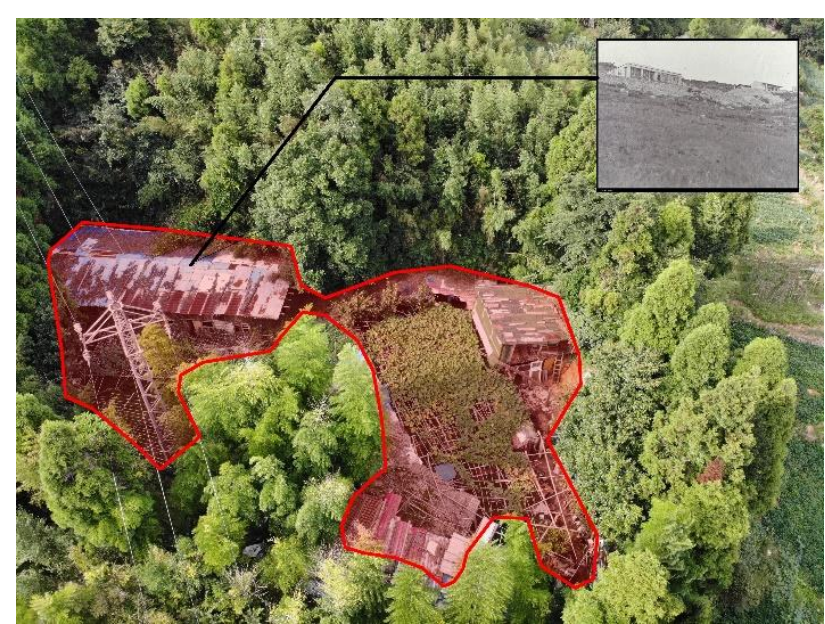

Figure 7 With the help of drone, the team found the site of No.370 cottage in Liangcuo, which was belonged to Dr. T. Rennie and the Imperial Maritime Customs of Fuzhou. The site is surrounded by trees, mostly are Cryptomeria, which can be identified easily by their special leaves. 


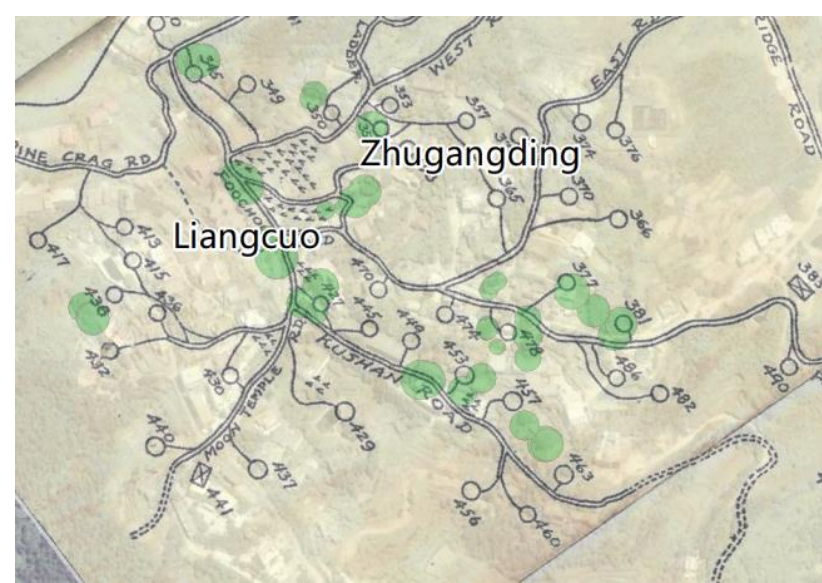

Figure 8 The existing Cryptomeria trees were marked by their crown diameters on the map, showing the relationship between the trees and the cottages

The research team used the drone to survey the existing trees first, then carried out on-site surveys. By measuring the crown diameters and breast diameters, the team was able to infer when the trees were planted and when the cottages were built. It was found that most of the existing trees were planted in pairs or rows in the southern courtyards of the cottages. Cryptomeria trees are distributed far more in Liangcuo and Houpulou areas where the Americans mainly lived (Figure 8).

Historically, the plantation in this area has always changed with the settlement pattern. The mountain springs in Liangcuo and Houpulou provided suitable environment for Cryptomeria. The altitude of Liangcuo and Houpulou area is relatively low, and the trees are not easily blown down by the typhoon. Most of the pine trees were cut down for fuel during the war period (Langhorn and Langhorn, 2014). Therefore, while historical photographs show that there were many pine trees in Qitouding area, but no old tree was found today.

\section{CONCLUSION}

This article integrated the use of drones, low-altitude imaging, photogrammetric modelling, geographic information database and other technologies to identify the transformation of the landscape pattern of Kuliang area and to analyse the mechanism behind it. It demonstrates that the cultural landscape research method based on digital spatial information technologies has the following advantages.

(1) The application of aerial photogrammetry and automatic 3D modelling technology can greatly reduce the workload of site surveys and provides effective methods for the restoration of historic landscape.

(2) The combination of HLC tool and digital technologies such as GPS tracking and aerial photogrammetry can integrate different types of data and reveal deeper insights about landscape patterns and their transformation.

(3) Aided by the GIS and spatial technology, the fragmented historical documents can be connected to provide a solid basis for the restoration and renewal of heritage sites.

\section{ACKNOWLEDGEMENNTS}

This research was supported by the Science Foundation of Ministry of Education of China (Youth Program) under Grant number 20YJC760054 and the National Natural Science Foundation of China (Youth Foundation) under Grant number 51608369.

\section{REFERENCES}

Caldwell, 1953. China Coast family. Chicago, Ill., Henry Regnery Co. 228p. ISBN 1131138481

Deegan, A. and G. Foard, 2008. Mapping Ancient Landscapes in Northamptonshire, Liverpool University Press. 180p. ISBN 9781905624423

Hill, A. C., 2019. Economical drone mapping for archaeology: Comparisons of efficiency and accuracy. Journal of Archaeological Science: Reports. Vol. 24, pp. 80-91., https://doi.org/10.1016/j.jasrep.2018.12.011

Johnston, T. and D. Erh, 1994. Near to Heaven: Western Architecture in China's Old Summer Resorts, Old China Hand Press. 135p. ISBN 9789627872047

Langhorn, K. and P. Langhorn, 2014. Letters from the dragon's head - Martha Wiley's China 1900-1947, Empty Bowl Press. ISBN 978-0-9824553-7-1

Macinnis, D., 1980. Midwest China Oral History Interviews Donald Macinnis. 56, M. C. Center. https://digitalcommons.luthersem.edu/china_histories/56/

Pitcher, R. P. W., 1895. A Sketch of Ku-Liang Mountain and Environments. Foochow, Methodist Mission Press. 34p. ISBN NONE

Richards-Rissetto, H., 2017. What can GIS + 3D mean for landscape archaeology? Journal of Archaeological Science. Vol. 84, pp. 10 - 21., https://doi.org/10.1016/j.jas.2017.05.005

Thomas, L., 2013. Cartographic and Literary Intersections: Digital Literary Cartographies, Digital Humanities, and Libraries and Archives. Journal of Map \& Geography Libraries. Vol. 9 (3), pp. 335-349., https://doi.org/10.1080/15420353.2013.823901

Turner, S., 2006. Historic Landscape Characterisation: A landscape archaeology for research, management and planning. Landscape Research. Vol. 31 (4), pp. 385-398., $10.1080 / 01426390601004376$

Welch, I., 2006. Amy Oxley: Letters from China. An Australian Missionary Nurse of the Church Missionary Association of New South Wales, Fujian Province, China, 1895-c1920, Australian National University.

Widener, J. M. and J. S. Reese, 2016. Mapping an American College Town: Integrating Archival Resources and Research in an Introductory GIS Course. Journal of Map \& Geography Libraries. Vol. 12 (3), pp. 238-257., https://doi.org/10.1080/15420353.2016.1195783

Zhuang, S., 1948. Three days in Kuliang. Central Daily News (Yongan).. 